Soviet education

\section{Helping towards better careers}

THE Soviet Union has introduced new rules for admission to higher education, designed to make university training more job-orientated. Instead of students being assessed simply on the sum of marks gained in their entrance examinations, an additional set of marks will also be awarded on the basis of interviews. The interview panel will assess each applicant's chances of success in his or her proposed field of study, and will provide guidance as to career choice. Commenting on the new procedures, the Moscow daily Pravda noted that they will give a clear advantage to young people who have begun to prepare themselves for their future profession while still attending secondary school.

The new admission rules are thus a continuation of the policy, introduced in the general education sector two years ago, of making study more closely related to future work.

In practical terms, the new rules will reduce the work-load on the entrants. Instead of having to offer four subjects, they will now only have to offer three: Russian language and literature (nonRussians may offer their native language if that is to be their language of tuition), a choice of mathematics, biology or social science (according to the student's chosen field) and the subject that the student eventually hopes to pursue.

Furthermore, it will be easier for wouldbe entrants to make applications to more than one university or institute. Until now, except for a handful of elite Moscow institutions, which held their entrance examinations in July, all examinations took place during August. As the Soviet Union has no national clearing-house system, this meant, effectively, that students keen to secure a place would aim at an institution rumoured to be easy on admissions. (This was particularly true of young men wanting to defer military service until after graduation). As a result many of the more cautious applicants set their sights rather lower than was necessary.

Now, according to Pravda, all higher education establishments in Moscow city, Moscow oblast' and Leningrad will, "as an experiment", hold their entrance examinations in July. This move, Pravda pointed out sententiously, "will allow those who did not pass the entrance examinations to one of the Central higher educational institutions to apply their efforts to gain entrance to a higher educational institution in some other town".

Vera Rich

\title{
US suit charges cancer causation
}

\section{Washington}

IN what may become a landmark personal injury case, the families of seven childhood cancer victims from Woburn, Massachusetts, are suing two large US corporations said to be responsible for the illnesses by polluting the local drinking water. Some 40 expert witnesses have been lined up by both sides to argue whether an excess of acute lymphocytic leukaemia and other conditions in east Woburn could be due to halogenated hydrocarbons that were found in two polluted wells in 1979 .

The case is one of the first in which it has been claimed that specific chemicals in drinking water caused specific illnesses. The wells, whose water mainly supplied east Woburn, tapped a different aquifer from Woburn's other wells. They were first used in 1967 and were closed in 1979 when trichloroethylene and tetrachloroethylene were found in the water at 200 parts per billion $\left(10^{9}\right)$ and 20 parts per billion respectively; other pollutants included $(1,1,1)$-trichloroethane, $(1,2)$-trans dichloroethylene and chloroform. The plaintiffs claim that the chemicals came from dumping or accidental spills at nearby plants owned by W.P. Grace and Company and Beatrice Foods. A third company, Unifirst, a dry-cleaning company, has already settled for $\$ 1$ million.

A local clergyman apparently first drew attention to a suspected leukaemia cluster in east Woburn, and the town's high incidence compared to national rates was subsequently confirmed in a study by the Massachusetts department of health. Nineteen cases were found where only six would have been expected; and renal cancer was also significantly elevated. The department concluded, however, that the "hypothesis suggesting that the increase in leukaemia incidence was associated with environmental hazards in Woburn . . . is neither supported nor refuted by the study findings".

But a more recent study by S.W. Lagakos, B.J. Wessen and M. Zelen of Harvard School of Public Health and Dana-Farber Cancer Institute does find a positive statistical association between access to water from the polluted wells and childhood leukaemia, as well as perinatal deaths and some congenital abnormalities. This study, in press with the Journal of the American Statistical Association, does not compare incidences in Woburn with those elsewhere, but establishes that within Woburn the diseases are found predominantly among those who drank more of the polluted water.

One of the pollutants, trichloroethane, is said recently to have been shown to cause leukaemia in rats. But a major weakness in the plaintiffs' case is that nothing is known about the nature and degree of pollution of the wells at any time other than 1979, when they were immediately closed. The known carcinogens that were then in the water supply were present in far lower concentrations than have been shown to cause cancers in laboratory animals and in human occupational health studies. But it is argued that the fetus may be more susceptible to carcinogens than the adult, and that plaintiffs are basing much of their case on recent immunological tests indicating abnormalities in the blood of the plaintiffs' families.

The trial, which is in its third week, is expected to last for several months. First it will be decided whether the defendants contributed to groundwater contamination; medical questions will be examined only if the answer to the first question is yes. Beatrice Foods is refusing to comment on detailed aspects of the litigation, although it is pointed out that the accusation is that the company allowed pollution of ground it owns adjacent to its plant. W.P. Grace says that its plant, which manufactures stainless steel food processing equipment, may have leaked small quantities of cleaning agents and degreasers onto its own property, but that investigations (including drilling 50 test wells) had shown this would not have found its way into the wells.

Tim Beardsley

\section{Europe's optical telescope for 1990}

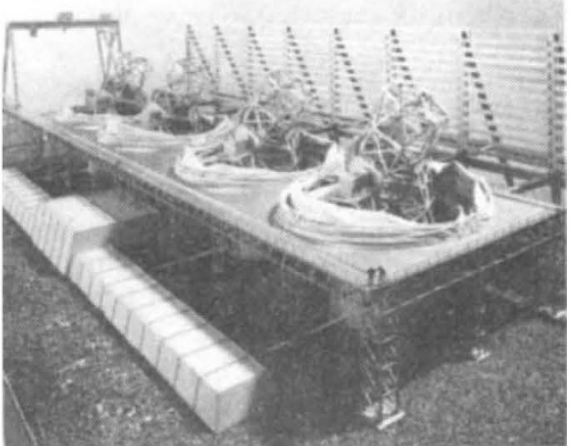

STILL just a model, this is the 16-metre optical telescope, the "Very Large Telescope", planned for the European Southern Observatory (ESO) in Chile. ESO technical committees are now meeting to establish exact specifications for the new instrument with the aim of presenting plans for a DM 300 million project to ESO member countries in time for work to start in 1987. The VLT is to be sited at an altitude of $2,400 \mathrm{~m}$, and the human figures in the above photograph put its size into perspective. 